Published by Al-Nahrain College of Medicine P-ISSN 1681-6579

E-ISSN 2224-4719

Email: iraqijms@colmed-alnahrain.edu.iq

http://www.colmed-alnahrain.edu.iq

http://www.iraqijms.net

Iraqi JMS 2018; Vol. 16(3)

\title{
Safe Primary Repair of Colorectal Injuries Without Diverting Colostomy
}

\author{
Taqi S. Atiyah FICMS \\ ${ }^{1}$ Dept. of Surgery, Collage of Medicine, Al-Nahrain University, Baghdad, Iraq
}

\begin{abstract}
\end{abstract}
Background Colostomy was used for treatment of colorectal injuries since the $2^{\text {nd }}$ World War, and it is a lifesaving procedure. There is a trend towards primary closure of colorectal injuries without colostomy in hemodynamically stable patients.

Objective To evaluate the safety of primary closure of colorectal injuries without colostomy in hemodynamically stable patients.

Methods

A cross sectional study was performed at Al-Imamein Al-Kadhimein Medical City for patients with colorectal injuries over the period from July 2011 to July 2017. Management was started with active resuscitation of the patient, explorative laparotomy (securing hemorrhage) and assessment of the colorectal injuries. When the patients were stable hemodynamically without associated injuries to other parts of the body; debridement of the wound edges of the colon and primary repair by suturing in two layers using 2/0 absorbable suture (polyglactin) on a round needle with or without colostomy. But if the patients were in a shock state with multiple associated injuries to other parts of the body, with severely devascularized lacerated colon; proximal colostomy was done as a part of damage control surgery with resection of the devascularized segment and suturing of the distal end of the colon.

Results A total of 231 patients sustained colorectal injuries; 143 (61.90\%) males and 88 (38.09\%) females. The age of the patients ranged from 6-76 years, mean age was 32.16 \pm 76 year. Colostomy was done for 134 (58.01\%) patients. Primary repair without colostomy were done for 97 (41.99\%) patients. Postoperative follow up of the patients treated with primary repair of colorectal injuries without colostomy were detected collection and leaking repaired segment of colon in 5 (5.15\%) patients. Re-exploration of the abdomen and colostomy were done for them. There was no mortality in patients treated without colostomy. The mortality rate was $9(6.71 \%)$ for patients treated by colostomy due to associated multiple traumas to other parts of the body.

Conclusion Primary repair of colorectal injuries without colostomy are safe in a hemodynamically stable patient without associated injuries to other parts of the body.

Keywords Colorectal injury, primary repair, colostomy.

Citation

Atiyah TS. Safe primary repair of colorectal injuries without diverting colostomy. Iraqi JMS. 2018; 16(3): 258-267. doi: 10.22578/IJMS.16.3.5

List of abbreviations: AAST = American Association for the Surgery of Trauma, ATLS = Advanced Trauma Life Support, $C T$ scan = Computerized tomography scan, FAST = Focused assessment with sonography for trauma.

\section{Introduction}

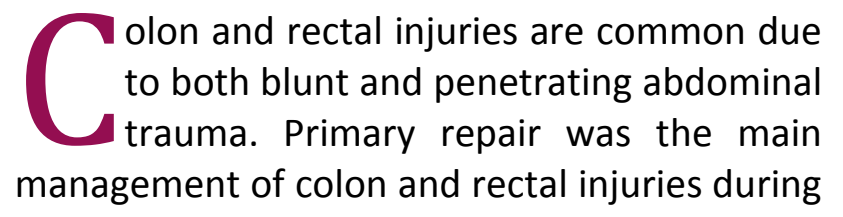

the First World War, and the mortality was $50 \%$. Colostomy was used for the first time during the second World War, and then it becomes an important operative procedure to save life of patients with colorectal injuries ${ }^{(1)}$. The surgical management of colon was changed during the late 1980's in selected patients with injury to the antimesenteric side of the colon, to repair and exteriorization of 
that segment of the colon with protection of the exteriorized colon and monitoring for three to five days to be returned back to the abdominal cavity after that time. This procedure was not used anymore because of the high failure rate of the repair and breakdown of the exteriorized segment, which may occur in about half of the patients who reexplored again and colostomy done for them (2). Direct penetrating injury to the colon and rectum by sharp objects are the most common cause of the injury (3), which may be due to knife, and more commonly gunshot and shell injuries during war time ${ }^{(4)}$. Motor vehicle crash, falls from a height, and direct abdominal trauma may also cause colon and rectal injuries. Colon injury must even be suspected in seat belt injury ${ }^{(5)}$. Blast injury and explosive device may cause contusions or tears of the colon which may end with its rupture ${ }^{(6)}$.

Management of patients with colorectal injuries start with resuscitation of the patient that follows the Advanced Trauma Life Support (ATLS) protocol (7), starting the resuscitation with securing the airway, breathing and circulation, treatment of shock, and a decision is made whether the patient may need immediate laparotomy. Detection of free fluid in the peritoneal cavity without solid organ injury by Computerized tomography (CT) scan may indicate colon and rectal injury in blunt abdominal trauma ${ }^{(8-10)}$.

According to the injury scoring scale (AAST) "the American Association for the Surgery of Trauma" (Table 1); when there is severe laceration that involves more than half the circumference of the colon with devascularization, resection of the devascularized colon and colostomy may be indicated. Anastomosis may be indicated if there are no devascularization and minimal fecal contamination. When the patient was sustained multiple trauma with shock, damage control surgery with stapling of the ends of the colon and planned second exploration may be indicated (11-13). After effective resuscitation and hemodynamic stability of the patient, reexploration of the patient should be done, and if the ends of the colon are viable with good blood supply, and approximation of both ends of the colon is possible, anastomosis may be done without tension, and the anastomosis site may be protected by omentum.

Table 1. Colon injury scale

\begin{tabular}{ccc}
\hline Grade & Type of injury & Description \\
\hline I & Hematoma & Contusion or hematoma without devascularization \\
II & Laceration & Partial thickness, no perforation \\
III & Laceration & Laceration $<50 \%$ of circumference \\
IV & Laceration & Laceration $\geq 50 \%$ of circumference without transection \\
V & Laceration & Transection of the colon \\
& Vascular & Transection of the colon with segmental tissue loss \\
\end{tabular}

Penetrating rectal injuries may be associated with injury to the urinary bladder and risk of fistula formation. Assessment of rectal injury was done according to AAST injury scale (Table 2). Colostomy is indicated if rectal injury is below the peritoneal reflection (14-20). Intraperitoneal rectal injury can be treated by primary repair. In some cases of extraperitoneal rectal injuries, which are not associated with injury to the urinary bladder and no pelvic vascular injuries can be treated without colostomy ${ }^{(21)}$. 
Table 2. Rectum injury scale

\begin{tabular}{ccc}
\hline Grade & Type of injury & Description \\
\hline I & Hematoma & Contusion or hematoma without devascularization \\
II & Laceration & Partial thickness laceration \\
III & Laceration & Laceration $<50 \%$ of circumference \\
IV & Laceration & Laceration $\geq 50 \%$ of circumference \\
V & Vascular & Devascularized segment \\
\hline
\end{tabular}

Not all abdominal wounds need explorative laparotomy especially if it is due to stab wounds. CT scan and laparoscopy can aid in decision making regarding indication for exploration $(22,23)$. Sometimes even gunshot may cause tangential injury to the abdomen without penetrating the peritoneal cavity (22). Closed observation and follow up of the patient clinically can determine the need for explorative laparotomy. If there are no signs of peritonitis and the patient not in a shock states with normal CT scan, it may be safe to continue with conservative treatment with follow up ${ }^{(24,25)}$. If the patient's condition deteriorates or signs of intra-abdominal organ involvement by injury appear, then laparotomy is indicated (2628). Most of shell injury and gunshot to the abdomen especially in war time need explorative laparotomy because any missed injury to the intestine and/or internal bleeding may have catastrophic complications and may lead to death of the patient.

Laparoscopy can be used for assessment of patient with abdominal trauma to exclude any colorectal injuries that may need explorative laparotomy. Isolated small transvers colon injuries by stab wound can be managed by laparoscopy; penetrating injuries to the diaphragm can be diagnosed and repaired with the aid of laparoscopy ${ }^{(29)}$. Endoluminal device to bypass the extraperitoneal rectal injury can avoid the need for colostomy.
The aim of the study was to evaluate the safety of primary closure of colorectal injuries without colostomy in hemodynamically stable patient.

\section{Methods}

After ethical approval of the study by Institution Review Board in the College of Medicine, Al-Nahrain University, a cross sectional study was performed at Al-Imamein Al-Kadhimein Medical City for patients with colorectal injuries, over the period from July 2011 to July 2017. Inclusion criteria include patients with abdominal trauma operated upon and had colorectal injuries.

Exclusion criteria include:

1- Patients not operated upon for abdominal trauma.

2- Patients whom were underwent colorectal operations for diseases other than trauma.

Patients were attending the emergency department of the hospital with acute abdominal trauma whether it is due to war (shells, bullets, explosions and blast injuries); or abdominal trauma due to civilian life (motor vehicle crash, fall from a height, or stab wound injury to the abdomen).

Management of patients started with resuscitation following the ATLS protocol, starting with securing the airway, breathing and circulation, treatment of shock (intravenous fluid, blood transfusion, insertion of Folly's catheter into the urinary bladder and collection of urine output, antibiotics, and other resuscitative management), ultrasound examination of the abdomen (FAST) "Focused 
Assessment with Sonography for Trauma" to detect the presence of free fluid in the abdomen, X-ray of the chest and X-ray of other parts of the body if indicated; and a decision is made whether the patient may need immediate laparotomy. Sometimes CT scan of the abdomen especially for patients with blunt trauma may be needed.

After hemodynamic stabilization of the patients, explorative laparotomy was done through a midline incision, securing hemorrhage, and dealing with other abdominal injuries (solid organ injuries like spleen, liver, kidney; or hollow organ injuries like the small bowel),exploration and assessment of colorectal injuries according to AAST injury scale was made in a systematic way with especial concern regarding the retroperitoneal colon in cases of penetrating injury to the back or flank and in a tangential wounds.

Primary repair of colorectal injuries was done by debridement of the wound edges and closure of the colorectal defect by suturing in two layers using 2/0 absorbable suture (polyglactin) (Vicryl suture) on a round needle; first continuous layer and second interrupted layer with invagination of the first layer).

Grade 1 injury were treated conservatively; Grade II patients were treated by debridement of the wound edges and primary repair with suturing in two layers using 2/0 vicryl suture on a round needle in two layers. For Grade III colorectal injuries; if the patients were stable hemodynamically and had isolated colon or rectal injury (without associated injuries to other abdominal organs nor associated injuries to other parts of the body like head injury or fractures), those patients were treated by primary repair without protecting colostomy; but if the patient was unstable hemodynamically (shock) or had associated injuries to other abdominal organs or the patient had multiple trauma to other parts of the body; then the primary repair was protected by proximal colostomy.

Patients with Grade IV, and Grade V injuries were presented with multiple associated trauma and injuries to other parts of the body, they were treated by resection of the devascularized segment with closure of the distal end of the colon and proximal end colostomy (Hartman's operation) as a part of damage control surgery.

The operative procedure done for the patients were either:

1. Debridement of the injured ends of the colorectal wounds and primary repair in two layers with or without proximal protective colostomy.

2. Resection of the devascularized segment with proximal end colostomy, and closure of the distal segment (Hartman's operation).

3. Right hemicolectomy with end ileostomy and mucous fistula of transvers colon.

Postoperative follow up of patients, by clinical abdominal examination, vital signs (fever, tachycardia), blood test white blood cell counts, and ultrasound examination of the abdomen looking for any signs of anastomotic leak or intra-abdominal collection.

All the patients were kept in the hospital postoperatively under closed observation till they had positive bowel motion, normal vital signs, and soft abdomen. Some patients with Grad III colorectal injuries who were treated by primary repair without protective colostomy were developed leaking anastomosis, and they were re-explored again and colostomy done for them.

Statistical analysis used:

- Categorical variables: frequency, and percentage \%s.

- Continuous variables: Means \pm standard deviation SD.

\section{Results}

Over the period from July 2011-July 2017, there were 687 laparotomies for abdominal trauma due to penetrating and blunt injuries; 231 patients of them were sustained colorectal injuries, the incidence of colorectal injuries was $33.62 \%$. There were $143(61.90 \%)$ males and 88 $(38.09 \%)$ female patients. The age of the patients ranged from 6-76 years, mean age was 32.16 year. Table (3) shows the age and gender of patients. There were 97 (41.99\%) patients 
treated by primary repair of colorectal injuries

for 134 (58.01\%) patients.

without colostomy, while colostomy was done

Table 3. The age and gender of patients with colorectal injuries

\begin{tabular}{cccc}
\hline Age group & Males & Females & Total \\
\hline $1-9$ years & $3(2.09 \%)$ & $1(1.13 \%)$ & $4(1.73 \%)$ \\
$10-19$ years & $16(11.18 \%)$ & $8(9.09 \%)$ & $24(10.38 \%)$ \\
$20-29$ years & $67(46.85 \%)$ & $34(38.63 \%)$ & $101(43.72 \%)$ \\
$30-39$ years & $28(19.58 \%)$ & $23(26.13 \%)$ & $50(21.64 \%)$ \\
$40-49$ years & $15(10.48 \%)$ & $17(19.31 \%)$ & $33(14.28 \%)$ \\
$59-59$ years & $7(4.89 \%)$ & $3(3.40 \%)$ & $10(4.32 \%)$ \\
$60-69$ years & $5(3.49 \%)$ & $1(1.13 \%)$ & $6(2.59 \%)$ \\
$70-79$ years & $2(1.39 \%)$ & $1(1.13 \%)$ & $3(1.29 \%)$ \\
\hline Total & $143(61.90 \%)$ & $88(38.09 \%)$ & 231 \\
\hline
\end{tabular}

The causes of colorectal injuries were due to war in 171 (74.02\%) patients (multiple shell injuries, explosions, high velocity bullet injuries and blast injury); while civilian injuries cause colorectal injuries in 60 (25.97\%) patients (motor crash injuries, fall from a height, and stab wound injuries). Table (4) shows the causes of colorectal injuries. The site of colorectal injuries in patients with colostomy were; in the right colon 29 (12.55\%), transverse colon 38 (16.45\%), left colon 23 (9.95\%), sigmoid colon $28(12.12 \%)$, and rectum 16 (6.92\%) patients.

The site of colorectal injuries in patients without colostomy were; in the right colon 22
(9.52\%), transvers colon 26 (11.25\%), left colon $9(3.89 \%)$, sigmoid colon $21(9.09 \%)$, and rectum 19 (8.22\%) patients. Table (5) shows the site of colorectal injuries.

The grades of colorectal injuries according to AAST injury scale were as follows: in patients with colostomy; there were 32 (13.85\%) patients sustained grade III injuries, 65 (28.13\%) patients grade IV injuries, and 37 (16.01\%) patients grade $V$ injuries. While the patients without colostomy; there were 27 (11.86\%) patients sustained grade I injuries, 39 $(16.88 \%)$ patients grade II injuries, and 31 (13.41\%) patients grade III injuries. Table (6) shows the Grades of colorectal injuries.

Table 4. The causes of colorectal injuries

\begin{tabular}{cccc}
\hline $\begin{array}{c}\text { Causes of abdominal } \\
\text { trauma }\end{array}$ & $\begin{array}{c}\text { Primary repair with } \\
\text { colostomy }\end{array}$ & $\begin{array}{c}\text { Primary repair without } \\
\text { colostomy }\end{array}$ & Total \\
\hline Motor vehicle crash & & $38(16.45 \%)$ & $38(16.45 \%)$ \\
Fall from a height & $9(3.89 \%)$ & $9(3.89 \%)$ \\
Stab wound injury & & $13(5.62 \%)$ & $13(5.62 \%)$ \\
War injury by & $112(48.48 \%)$ & $31(13.41 \%)$ & $143(61.90 \%)$ \\
Shells (explosions) & $19(8.22 \%)$ & $6(2.59 \%)$ & $25(10.82 \%)$ \\
high velocity bullets & $3(1.29 \%)$ & & $3(1.29 \%)$ \\
Blast injury & $134(58.01 \%)$ & $97(41.99 \%)$ & 231 \\
\hline Total & &
\end{tabular}


Table 5. The sites of colorectal injuries

\begin{tabular}{cccc}
\hline Site of injury & $\begin{array}{c}\text { Primary repair with } \\
\text { colostomy }\end{array}$ & $\begin{array}{c}\text { Primary repair without } \\
\text { colostomy }\end{array}$ & Total \\
\hline Right colon & $29(12.55 \%)$ & $22(9.52 \%)$ & $51(22.07 \%)$ \\
Transvers colon & $38(16.45 \%)$ & $26(11.25 \%)$ & $64(27.70 \%)$ \\
Left colon & $23(9.95 \%)$ & $9(3.89 \%)$ & $32(13.85 \%)$ \\
Sigmoid colon & $28(12.12 \%)$ & $21(9.09 \%)$ & $49(21.21 \%)$ \\
Rectum & $16(6.92 \%)$ & $19(8.22 \%)$ & $35(15.15 \%)$ \\
\hline Total & $134(58.01 \%)$ & $97(41.99 \%)$ & 231 \\
\hline
\end{tabular}

Table 6. The grades of colorectal injuries in both groups

\begin{tabular}{cccc}
\hline Site of injury & $\begin{array}{c}\text { Primary repair with } \\
\text { colostomy }\end{array}$ & $\begin{array}{c}\text { Primary repair without } \\
\text { colostomy }\end{array}$ & Total \\
\hline Grade I & & $27(11.86 \%)$ & $27(11.68 \%)$ \\
Grade II & $32(13.85 \%)$ & $39(16.88 \%)$ & $39(16.88 \%)$ \\
Grade III & $65(28.13 \%)$ & $31(13.41 \%)$ & $63(27.27 \%)$ \\
Grade IV & $37(16.01 \%)$ & & $65(28.13)$ \\
Grade V & $134(58.01 \%)$ & $97(41.99 \%)$ & $37(16.01)$ \\
\hline Total & & & 231 \\
\hline
\end{tabular}

There were 5 (5.15\%) patients treated by primary repair without colostomy was developed collection and anastomotic leak postoperatively, all of them were grade III injuries. Re-exploration of the abdomen and proximal protective colostomy were done for them. So, the failure rate was 5 (5.15\%) patients. There was no mortality in patients treated by primary repair without colostomy, because those patients were stable hemodynamically and were highly selected group without trauma to other parts of the body.

The mortality rate was $9(6.71 \%)$ patients; all of them were died due to the associated severe trauma to other parts of the body and their complications (head and chest injuries with fractured long bones).

\section{Discussion}

During the decades of war in Iraq, thousands of patients underwent laparotomy for colorectal injuries; the vast majority of them were managed by repair with colostomy. Even inside cities of Iraq, there were many explosions, which cause severe penetrating abdominal injuries for people in all age groups. Although colostomy is life saving and simple procedure to divert fecal material away from the abdominal cavity, but it carries its complications, and needs second operation for closure. Recently there is a trend towards primary repair without diverting colostomy in especial circumstances.

In this study, there were 687 laparotomies for abdominal trauma due to penetrating and blunt injuries; 231 patients were sustained colorectal injuries, the incidence of colorectal injuries was $33 \%$. The gender of the patients was 143 (61.90\%) males and 88 (38.09\%) female patients. The age of the patients ranged from 6-76 years, mean age was 32.16 years. Children, females, and elderly people were affected by explosions and shell injuries inside cities while young male patients were affected during fighting in combat in the war 
Destructive injuries were due to war injury (explosions and high velocity bullet injuries), while non-destructive injuries were due to civilian injuries (motor crash injuries, fall from a height and stab wound injuries).

In review of literatures; treatment of the destructive colorectal injuries may require resection of the destructed segment ${ }^{(30)}$. In the civilian life $80-90 \%$ of colorectal trauma are non-destructive ${ }^{(30)}$, while in war time $72 \%$ are destructive (6). About $60-93 \%$ of the nondestructive colorectal injuries can be managed with primary repair, but the management of destructive injuries is still controversial (31). Missed colorectal injuries may lead to fatal septic complications; therefor there should be high index of suspicion of colorectal injuries in patient with abdominal trauma (32).

There were 39 (16.88\%) patients with grade II injuries were treated by debridement of the wound edges and primary repair with suturing in two layers using $2 / 0$ vicryl suture on a round needle in two layers without colostomy. There were 63 (27.27\%) patients had grade III colorectal injuries; about half of them 32 (13.85\%) patient were treated by primary repair and protective proximal colostomy, because there were associated multiple traumas to other parts of the body (head injury, chest injury, fractured long bones), and the patients were unstable hemodynamically (shock state), and there was severe fecal contamination with prolonged period of time from the injury to the time of laparotomy.

While the other $31(13.41 \%)$ patients with grade III colorectal injuries were treated with primary repair without colostomy because the patients were stable hemodynamically, and there were no associated injuries to other parts of the body with little fecal contamination and short period of time from the injury to the time of laparotomy.

Grades IV, V, are serious injuries, and were associated with multiple injuries to other intraabdominal organ (lacerations of liver, spleen, and pancreas), as well as multiple trauma to other parts of the body (head and chest injuries with fractured long bones), those patients were treated by resection of the severely devascularized lacerated segment of the colon and closure of the distal segment with protective proximal end colostomy to save life as a rapid and safe procedure (part of damage control surgery).

Damage control surgery was used to save life of multiply injured patients (control bleeding and fecal contamination due to bowel injury), and postponed definitive reconstructive surgery in unstable patient to prevent rapid progress to death due to hypothermia, coagulopathy, and acidosis (33).

On the contrary to the above data, one study performed on 2009 showed that there were no differences whether colostomy done or not done for patients underwent damage control surgery with primary repair and anastomosis of colorectal injury ${ }^{(12)}$.

There were $5(5.15 \%)$ patients treated by primary repair without colostomy was developed collection and anastomotic leak postoperatively, all of them had grade III colorectal injuries. Re-exploration of the abdomen and protective proximal colostomy were done for them. So, the failure rate was $5.15 \%$.

There were $9(6.71 \%)$ patients died in patients treated with colostomy due to severe trauma to other parts of the body (head injury, chest injury, fractures, and severe trauma and lacerations to other abdominal organs with shock and sepsis). There was no mortality in patients treated without colostomy because they were highly selected group and stable hemodynamically without associated injuries to other parts of the body.

Ott advised that if the patient is unsuitable for primary repair and anastomosis, it is better to do fecal diversion with colostomy or ileostomy (13). Broad-spectrum antibiotics which should cover aerobic and anaerobic bacteria are mandatory once a colorectal injury was diagnosed and the antibiotics should be continued for at least one day after control of fecal contamination (34). Retrospective studies showed that excessive intravenous fluids more than 10.5 liters in the first three postoperative days have been associated with a fivefold increased risk of leaking anastomosis (35).

The incidence of colorectal injuries in this study was $33.62 \%$, while the incidence of isolated 
colorectal trauma in some studies is less than $1 \%$ from all the trauma patients, $43.9 \%$ following blunt abdominal trauma, and $56.1 \%$ following penetrating abdominal trauma with $25.6 \%$ mortality rate ${ }^{(36)}$. During wartime the incidence of colorectal injuries was increases to 5-10\%. An American study of over 3,400 injured soldiers during Iraqi invasion shows colorectal injuries in $5.1 \%$ of them ${ }^{(37,38)}$. Other American study on 2010 revealed that penetrating colorectal injuries occurred in $71 \%$, blast injuries in 23\%, and blunt injury in 5 percent ${ }^{(6)}$. The incidence of colorectal injuries is much lower in civilian life, and it is around $0.6-3 \%$ in North American studies, but the mortality rate depends on the mechanism of injury, and there was a high mortality rate around $10-25.6 \%$ following high-energy trauma, while the mortality rate was $0.1-0.5 \%$ following blunt abdominal trauma $(39,40)$. The mechanisms of colorectal injuries are significant in determining the severity of the injury; the incidence of blunt trauma in urban hospitals is low, and it is around $0.02 \%(41)$.

There are many different modalities and approaches to patients with multiple traumas involving colorectal injuries (42). Extra peritoneal rectal injuries and severe damage to anal canal and perineum may need colostomy which is important for their healing.

One of the previous retrospective studies showed that there were $2.4 \%$ incidence of leaking anastomosis in civilian trauma injuries (43), but during wartime the incidence is much higher and it were $13-30 \%$ due to the differences in mechanism of colorectal injuries (more destructive injuries) and the associated other injuries $(44,45)$. Shock with septic complications increases the mortality rate ${ }^{(32)}$.

Although fecal diversion and colostomy may be advised during wartime, one study on 2009 advised primary repair of all colorectal injuries (46).

Mesenteric hematoma or colonic wall hematoma (grade I) need observation unless the hematoma is expanding or there is devascularization of the wall of the colon (47). Large mesenteric hematoma should be assessed properly to exclude serious vascular injury ${ }^{(48)}$.
One large study from 14 trauma centers covering 517 patients revealed that leaking anastomosis and intraperitoneal sepsis as a complications of damage control surgery was increased with large volume intravenous fluid resuscitation and increased number of reexplorative laparotomies (49).

Although colostomy may be lifesaving in colorectal injuries, but colostomy reversal is not free from complications. One of the studies showed that complication rate $25-44 \%$, mortality rate $0.65-4.3 \%$, and higher mortality rate $(4.7 \%)$ following Hartman's operation reversal ${ }^{(50)}$. The complications were including minor wound infections (21.8\%), ileus $(5.7 \%)$, anastomotic leak (13.0\%) without enterocutaneous fistula, small bowel obstruction (11.5\%), anastomotic leak with enterocutaneous fistula formation (3.8\%), and intra-abdominal abscess (1.1\%). The complication rates increased when the patient had low serum albumin level or the patient used steroid treatment. Some patients may never have their stoma reversed (51).

This study concluded that primary repair of colorectal injuries without colostomy were safe in patients with grade III injuries (who were stable hemodynamically, without associated severe trauma to other parts of the body, with short period of time from the injury to the time of laparotomy, and with little fecal contamination.

\section{Acknowledgments}

None.

\section{Conflict of interest}

None.

\section{Funding}

None.

\section{References}

1. Berne JD, Velmahos GC, Chan LS, et al. The high morbidity of colostomy closure after trauma: Further support for the primary repair of colon injuries. Surgery. 1998; 123(2): 157-64.

2. Hatch $Q$, Causey $M$, Martin $M$, et al. Outcomes after colon trauma in the 21st century: An analysis of the U.S. National Trauma Data Bank. Surgery. 2013; 154(2): 397-403. doi: 10.1016/j.surg.2013.05.011. 
3. Braveman JM, Malangoni MA. Contemporary Management of penetrating colon trauma. Sem Colon Rectal Surg. 2004; 15(2): 112-8. doi: https://doi.org/10.1053/j.scrs.2004.10.006.

4. Causey MW, Rivadeneira DE, Steele SR, et al. Historical and current trends in colon trauma clinics. Clin Colon Rectal Surg. 2012; 25(4): 189-99. doi: 10.1055/s-0032-1329389

5. Fakhry SM, Watts DD, Luchette FA et al. Current diagnostic approaches lack sensitivity in the diagnosis of perforated blunt small bowel injury: analysis from 275,557 trauma admissions from the EAST multiinstitutional HVI trial. J Trauma. 2003; 54(2): 295-306. doi: 10.1097/01.TA.0000046256.80836.AA.

6. Cho SD, Kiraly LN, Flaherty SF, et al. Management of colonic injuries in the combat theater. Dis Colon Rectum. 2010; 53(5): 728-34. doi: 10.1007/DCR.0b013e3181d326fd.

7. American College of Surgeons. Advanced Trauma Life Support ATLS student course manual. 9th ed. Chicago, Illinois American ACS Committee on Trauma; 2012.

8. Walker ML, Akpele I, Spence SD, et al. The role of repeat computed tomography scan in the evaluation of blunt bowel injury. Am Surg. 2012; 78(9): 979-85.

9. Dreizin D, Boscak A, Anstadt MJ, et al. Penetrating colorectal injuries: diagnostic performance of multidetector CT with trajectography. Radiology. 2016; 281(3): 749-762. doi: 10.1148/radiol.2015152335.

10. Johnson E K, Judge T, Lundy J, Meyermann M. Diagnostic pelvic computed tomography in the rectalinjured combat casualty. Mil Med. 2008; 173(3): 2939.

11. Miller PR, Chang MC, Hoth JJ, et al. Colonic resection in the setting of damage control laparotomy: is delayed anastomosis safe? Am Surg. 2007; 73(6): 606-9; discussion 609-10.

12. Weinberg JA, Griffin RL, Vandromme MJ, et al. Management of colon wounds in the setting of damage control laparotomy: a cautionary tale. J Trauma. 2009; 67(5): 929-35. doi: 10.1097/TA.0b013e3181991ab0.

13. Ott MM, Norris PR, Diaz JJ, et al. Colon anastomosis after damage control laparotomy: recommendations from 174 trauma colectomies. J Trauma. 2011; 70(3): 595-602. doi: 10.1097/TA.0b013e31820b5dbf.

14. Sharpe JP, Magnotti LJ, Winberg JA, et. al. Applicability of an established management algorithm for colon injuries following blunt trauma. J Trauma Acute Care Surg. 2013; 74(2): 419-24; discussion 424-5. doi: 10.1097/TA.0b013e31827a36e9.

15. Sharpe JP, Magnotti LJ, Weinberg JA, et al. Impact of location on outcome after penetrating colon injuries. J Trauma Acute Care Surg. 2012; 73(6): 1428-32; discussion 1433. doi: 10.1097/TA.0b013e31825bff06.

16. Merlino Jl, Rynolds HC. Management of rectal injuries. Sem Colon Rectal Surg. 2004; 15(2): 95-104.
17. Burch JM, Feliciano DV, Mattox KL. Colostomy and drainage for Civilian Rectal injuries: is that all? Ann Surg. 1989; 209(5): 600-10; discussion 610-1.

18. Navsaria PH, Edu S, Nicol AJ. Civilian extraperitoneal rectal gunshot wounds: surgical management made simpler World J. Surg. 2007; 31(6): 1345-51.

19. Gonzalez RP, Phelan H 3rd, Hassan M, et al. Is fecal diversion necessary for non-destructive penetrating extraperitoneal rectal injuries? J Trauma. 2006; 61(4): 815-9. doi: 10.1097/01.ta.0000239497.96387.9d

20. Gonzalez RP, Turk B. Surgical options in colorectal injuries. Scand J Surg. 2002; 91(1): 87-91.

21. Gash K, Suradkar K, Pappou E, et al. Outcomes of rectal trauma injuries: the USA National Trauma Data Bank Abstract. The association of Coloproctology of Great Britain and Ireland. Conference paper; 2016.

22. Como JJ, Bokhari F, Chiu WC, et al. Penetrating abdominal trauma selective non-operative management. Eastern Association for the Surgery of Trauma Guidelines. J Trauma. 2010; 68(3): 721-33.

23. Biffl WL, Kaups KL, Pham TN, et al. Validating the Western Trauma Association Algorithm for Managing patients with anterior abdominal stab wounds: A Western Trauma Association Multicenter trial. J Trauma. 2011; 71(6): 1494-502. doi: 10.1097/TA.0b013e31823ba1de.

24. Fikry K, Velmahos GC, Bramos A, et al. Successful selective nonoperative management of abdominal gunshot wounds despite low penetrating trauma volumes. Arch Surg. 2011; 146(5): 528-32. doi: 10.1001/archsurg.2011.94.

25. Navsaria PH, Nicol AJ, Edu S, et al. Selective nonoperative management in 1106 patients with abdominal gunshot wounds: conclusions on safety, efficacy, and the role of selective CT imaging in a prospective single-center study. Ann Surg. 2015; 261(4): 760-4. doi: 10.1097/SLA.0000000000000879.

26. Lamb CM, Garner LP. Selective non-operative management of civilian gunshot wounds to the abdomen: a systematic review of the evidence. Injury. 2014; 45(4): 659-66. doi: 10.1016/j.injury.2013.07.008. Epub 2013 Jul 27.

27. Peponis T, Kasotakis G, Yu J, et al. Selective nonoperative management of abdominal gunshot wounds from heresy to adoption: a multicenter study of the research consortium of New England centers for trauma. J Am Coll Surg. 2017; 224(6): 1036-1045. doi: 10.1016/j.jamcollsurg.2016.12.055.

28. Zafar SN, Rushing A, Haut ER, et al. Outcome of selective non-operative management of penetrating abdominal injuries from North American National Trauma Database. Br J Surg. 2012; 99 Suppl 1: 15564. doi: 10.1002/bjs.7735.

29. Lim KH, Chung BS, Kim JY, et al. Laparoscopic surgery in abdominal trauma: a single center review of a 7year experience. World J Emerg Surg. 2015; 10: 16. doi: 10.1186/s13017-015-0007-8.

30. Stewart RM, Rosenthal D. Colorectal trauma. In: Corman ML (ed). Colon and rectal surgery. 
Philadelphia, PA: Lippincott Williams \& Wilkins; 2005. p. 427-49.

31. Cleary RK, Pomerantz RA, Lampman RM. Colon and rectal injuries. Dis Colon Rectum 2006; 49(8): 120322. doi: 10.1007/s10350-006-0620-y.

32. Welling DR, Duncan JE. Stomas and trauma. Clin Colon Rectal Surg. 2008; 21(1): 45-52. doi: 10.1055/s2008-1055321.

33. Cotton BA, Reddy N, Hatch QM, et al. Damage control resuscitation is associated with a reduction in resuscitation volumes and improvement in survival in 390 damage control laparotomy patients. Ann Surg. 2011; 254(4): 598-605. doi: 10.1097/SLA.0b013e318230089e.

34. Hospenthal DR, Murray CK, Andersen RC, et al. Guidelines for the prevention of infection after combat-related injuries. J Trauma. 2008; 64(3 Suppl): S211-20. doi: 10.1097/TA.0b013e318163c421.

35. Schnüriger $B$, Inaba $K, W u T$, et al. Crystalloids after primary colon resection and anastomosis at initial trauma laparotomy: excessive volumes are associated with anastomotic leakage. J Trauma. 2011; 70(3): 603-10. doi: 10.1097/TA.0b013e3182092abb.

36. Brady RR, O'Neill S, Berry O, et al. Traumatic injury to the colon and rectum in Scotland: demographics and outcome. Colorectal Dis. 2012; 14(1): e16-22. doi: 10.1111/j.1463-1318.2011.02753.x.

37. Hudolin $\mathrm{T}$, Hudolin I. The role of primary repair for colonic injuries in wartime. Br J Surg. 2005; 92(5): 643-7.

38. Steele SR, Wolcott KE, Mullenix PS, et al. Colon and rectal injuries during Operation Iraqi Freedom: are there any changing trends in management or outcome? doi: 10.1007/s10350-007-0235-4.

39. Steel M, Danne $P$, Jones I. Colon trauma: Royal Melbourne Hospital experience. ANZ J Surg. 2002; 72(5): 357-9.

40. Ng AK, Simons RK, Torreggiani WC, et al. Intraabdominal free fluid without solid organ injury in blunt abdominal trauma: an indication for laparotomy. J Trauma. 2002;52(6):1134-1140.

41. Govender M, Madiba TE. Current management of large bowel injuries and factors influencing outcome. Injury. 2010; 41(1): 58-63. doi: 10.1016/j.injury.2009.01.128.

42. Welling DR, Hutton JE, Minken SL, et al. Diversion defended-military colon trauma. J Trauma. 2008;
64(4):

$1119-22$.

doi:

10.1097/01.ta.0000222647.98722.9d

43. Strada G, Raad L, Belloni G, et al. Large bowel perforations in war surgery: one-stage treatment in a field hospital. Int J Colorectal Dis. 1993; 8(4): 213-6.

44. Saghafinia M, Nafissi N, Motamedi M RK. et al. Assessment and outcome of 496 penetrating gastrointestinal warfare injuries. J R Army Med Corps. 2010; 156(1): 25-7.

45. Duncan JE, Corwin $\mathrm{CH}$, Sweeney WB. et al. Management of colorectal injuries during Operation Iraqi Freedom: patterns of stoma usage. J Trauma. 2008; 64(4): 1043-7. doi: 10.1097/TA.0b013e318047c064.

46. DuBose J. Colonic trauma: indications for diversion vs. repair. J Gastrointest Surg. 2009; 13(3): 403-4. doi: 10.1007/s11605-008-0783-5.

47. Agaba EA, Zaidi RM, Ramzy P, et al. Laparoscopic Hartmann's procedure: a viable option for treatment of acutely perforated diverticulitis. Surg Endosc. 2009 Jul; 23(7): 1483-6. doi: 10.1007/s00464-009-0380-z.

48. Causey MW, Oguntoye $M$, Steele SR. Incidence of complications following colectomy with mesenteric closure versus no mesenteric closure: does it really matter? J Surg Res. 2011; 171(2): 571-5. doi: 10.1016/j.jss.2010.06.002.

49. Bradley MJ, Dubose JJ, Scalea TM, et al. Independent predictors of enteric fistula and abdominal sepsis after damage control laparotomy: results from the prospective AAST Open Abdomen registry. JAMA Surg. 2013; 148(10): 947-54. doi: 10.1001/jamasurg.2013.2514.

50. Kaiser AM, Israelit S, Klaristenfeld D, et al. Morbidity of ostomy takedown. J Gastrointest Surg. 2008; 12(3): 437-41. doi: 10.1007/s11605-007-0457-8.

51. Vermeulen J, Coene PP, Van Hout NM, et al. Restoration of bowel continuity after surgery for acute perforated diverticulitis: should Hartmann's procedure be considered a one-stage procedure? Colorectal Dis. 2009; 11(6):619-24. doi: 10.1111/j.1463-1318.2008.01667.x.

\section{E-mail: taqi.atyia@yahoo.com taqi.atiyah@colmed-alnahrain.edu.iq \\ Received Dec. $3^{\text {rd }} 2017$ \\ Accepted Dec. $25^{\text {th }} 2017$}

